\title{
De la literatura anglesa a la catalana: un canvi de circuit lector en el relat per a adolescents
}

\author{
Gemma Lluch \\ ERI Lectura. Universitat de València \\ Gemma.Lluch@uv.es \\ Recibido: febrero de 2013. Aceptado: març de 2013
}

Resum: L'article analitza com es relacionen els relats escrits per a adolescents en la cultura escrita en anglès i les traduccions al català. Partim de l'anàlisi de tres relats claus de la història de la lectura i en completem l'anàlisi amb la investigació dels circuits de lectura en català que acullen la traducció dels relats. La investigació vol conèixer com s'hi adapten, en quin circuit funcionen i quins canvis generen en la cultura d'arribada. En les conclusions mostrarem com aquests relats en arribar al circuit de lectura en català representen models de comunicació literari i creen circuits de lectura diferents de la cultura d'origen. Són circuits lligats al poder polític, a la selecció captiva del docent a l'escola o al mercat.

\begin{abstract}
The article analyses the links between the stories written for teens in an English culture and their translation into Catalan. Our starting point is the analysis of three key stories in the history of reading, and we complete this analysis with the investigation of circuit readers in Catalan that deal with translations of the accounts. The main aim of this research is to analyse how do they adapt to a new and different society, what is the context where they operate and what changes do they produce into the target culture. The conclusions show to what extend these translated stories represent a model of literary communication once they enter the Catalan circuit readers and how do they create different circuit readers than the ones created by the original culture. These circuits are always linked to political power, selection of teachers at school or at the cultural market.
\end{abstract}

Paraules clau: Traducció, Literatura per a infants i joves catalana, circuit lector, mercat cultural, noucentisme.

Keyboards: Translation, Children's literature Catalan circuit reader, cultural market, noucentism. 


\section{CONTEXTUALITZACIÓ DE LA INVESTIGACIÓ}

L'article analitza les relacions que hi ha entre els relats per a adolescents escrits des de l'anglès i les seves traduccions al català. Per respondre-hi, analitzarem tres relats claus de la literatura per a adolescents en anglès que formen part, de manera diferent, de la història de la lectura i en completem l'anàlisi amb la investigació sobre els circuits de lectura en català que acullen la traducció dels relats. Els tres relats elegits són Alice's Adventures in Wonderland (1865), George's marvellous medicine (1981) i Harry Potter (1997-2007). Un corpus format per tres narracions que han traspassat els límits d'una llengua i d'una cultura i representen tres moments claus de la lectura per a infants i joves tant en la cultura d'origen com en la d'arribada.

Les preguntes que volem contestar són: què ocorre quan passen d'una cultura a una altra?, com s'hi adapten, com les acull la cultura d'arribada?, quin espai ocupen i en quin circuit funcionen? Per contestar-les partim de les dades d'anàlisis anteriors (Lluch 2003, 2009, 2010 i 2013), dels estudis sobre la infantesa de J. Gelis (1985) o de la lectura Roger Chartier (1993, 2000); dels treballs de sociologia de la literatura de Robert Escarpit $(1968,1971)$, les històries sobre el llibre d'Hipólito Escolar (1988), Joan Fuster (1992) o Cendán Pazos (1986); les anàlisis històriques de Rovira $(1976,1988)$ i Valriu (1994); les anàlisis sobre el relat paraliterari de Couégnas (1992), Boyer (1992), Nash (1990), Vogler (2002), Rudd (2000), Zipes (2001) Stephens (1992) o Bobes (1992) i dels treballs sobre la traducció de Sellent (1998), Toutain (1997) o González Davies (1998 i 2003). Aquests estudis construeixen el marc metodològic que permet obtenir i interpretar les dades de les obres i els contextos de lectura, d'escriptura i de traducció.

La investigació mostrarà com aquests relats, en arribar al circuit de lectura en català, representen models de comunicació literària i creen circuits de lectura diferents dels que tenien en la cultura d'origen; abans però, és important descriure breument el context històric que ajudarà a interpretar el mapa de la investigació i contextualitzar cada circuit lector.

\section{EL MARC HISTÒRIC DEL CORPUS D'ANÀLISI}

En el segle XIX s'escriuen clàssics com ara Alice's Adventures in Wonderland (1865) de Lewis Carroll i un llarg etcètera de llibres pensats i editats específicament per a l'oci i l'educació del públic infantil. Però la lectura per a infants en català és més tardana. La Ley de Instrucción Pública impulsada per Claudio Moyano instaura el 1857 l'ensenyament obligatori dels 6 als 10 anys i fixa les matèries que calia estudiar: principis de religió i moral, lectura, escriptura, aritmètica i com a única gramàtica que podia ensenyar-se a les escoles, la gramàtica castellana:

A partir d'aquesta data proliferen les notícies referides a la coerció exercida des de l'escola en contra del català, no ja en l'ús formal oral i escrit, sinó fins i tot en l'ús oral espontani, dins i fora de l'escola. L'estat no sols fa 
circular textos jurídics i funcionals en l'àmbit educatiu, sinó que hi imposa un material escolar abocat a la castellanització total de l'escola (Ferrando i Nicolàs 2005: 324).

Hem d'esperar fins l'inici del segle XX per poder parlar de la publicació de relats d'interès adreçats als infants justament en un moment històric en el qual Europa ja compta amb una producció de literatura per a infants suficient per poder parlar de circuits lectors consolidats. És en aquest període quan arriba la traducció d'Alicia de les mans del millor poeta i intel-lectual. No és un fet estrany: cal recordar que en el primer terç del segle XX:

En l'àmbit literari, l'activitat traductora va adquirir des de molt aviat un paper
primordial com a instrument per dur a terme els objectius que l'empresa s'ha-
via imposat. La voluntat d'aproximar-se a la cultura universal per mitjà de les
traduccions ja havia estat present en les generacions immediatament anteriors,
però en el cas dels noucentistes no solament es va intensificar, sinó que s'hi va
afegir, i potser amb més protagonisme i tot, una estratègia nova i clarament
definida: la de contribuir, amb les versions al català de textos universals, a la
fixació d'un model de llengua literària moderna a partir de la codificació gra-
matical de Pompeu Fabra (Sellent 1998: 24).

La forta producció de la primera meitat del segle passat finalitza amb la dictadura de Franco i el llarg parèntesi de prohibicions i silencis no es tanca fins el 1962. En aquesta data es publica el primer número de la revista infantil Cavall Fort i, un any després, s'inicia la producció de l'editorial La Galera.

Els setanta introdueixen dos fenòmens nous: el primer, la publicació del primer best-seller per a adolescents, Mecanoscrit del segon origen de Manuel de Pedrolo, editat el 1974 a Edicions 62. I el segon, la recomanació del llibre a l'escola que crea un circuit de lectura singular i diferenciat de l'adult. En la dècada dels setanta, el català entra en l'ensenyament i s'instaura la recomanació de llibres de lectura en tots els nivells educatius. Com manifesta Castellet «La recomanació a les escoles és determinant i, sobretot a partir de 1981, la venda de llibres es multiplica. [...] Aquest fet és determinant per a autors como Calders, Pedrolo, Mercè Rodoreda i impulsa la venda de Salvador Espriu» (VilaSanjuan 2003: 258). En aquest circuit, una vegada consolidat, analitzarem la traducció de George's marvellous medicine (1981), La meravellosa medicina d'en Jordi (1986), escrita per Roald Dahl (1916-1990).

El final del segle XX i principi del XXI dibuixa un mapa diferent en la literatura per a infants, conseqüència de l'èxit de vendes de la saga protagonitzada per Harry Potter (1997-2007). Els relats d'aquest personatge inauguren el fenomen de la venda massiva de llibres a través de l'anomenada compra per impuls, la lectura es deslocalitza de l'escola per passar al mercat i es lliura de la tutela del docent per passar a la del màrqueting. Un circuit que després de la saga Potter es consolida amb èxits com The Hunger Games (2008) i la traducció Els jocs de la fam (2009). 
Així doncs, aquest és el context històric en el qual analitzem les traduccions de les obres elegides: si Alice's Adventures in Wonderland se situa en un circuit de lectura dominat per la política, La medicina.. entra en el de la selecció captiva a través de la recomanació de llibres a l'escola. I Harry Potter inaugura en la cultura d'arribada, aparentment, la llibertat del lector que consolida i amplia els futurs èxits com Els jocs de la fam.

\section{ALICE'S ADVENTURES IN WONDERLAND. LECTURA I CONSTRUCCIÓ NACIONAL}

Possiblement, el llibre anglès més citat per a infants ha estat Alice's d'Adventures in Wonderland, escrit el 1865 per Lewis Carrol, pseudònim de Charles Dodgson (1832-1898). El text exigeix una competència enciclopèdica restringida a un infant educat sota el sistema victorià del segle XIX. Ens referim a la coneixença dels textos utilitzats a l'escola, de la literatura moralista més consumida pels infants d'aleshores i també d'una sèrie de normes educatives, de conducta $\mathrm{i}$ bons costums que eren imprescindibles per un infant que formarà part de la societat burgesa anglesa del XIX. Aquest marc funciona com a hipotext amb el qual es manté una relació de transvestisme burlesc amb una clara intenció de transformació temàtica, sobretot de transvalorització ideològica. Emer O'Sullivan (2001) en analitzar les traduccions de l'obra a l'alemany veu les dificultats següents:

Alice in Wonderland is full of explicit and implicit cultural references which present German translators with further difficulties. These include topographical elements, eating habits, references to historical or cultural figures, regional and social accents, currency, weights and measures and names (O’Sullivan 2001: 13).

González Davies (1998) analitza un exemple d'aquestes dificultats: l'humor que hi ha a l'obra de Carroll. L'autora descriu la manera de resoldre els problemes de traducció:

Es tracta de cobrir, per una part, «els buits referencials» de què parlava Dagut (Rabadán 1991: 167), és a dir, les àrees d'experiència no compartida. Per l'altra, es tracta de crear un efecte lúdic similar en el text d'arribada. Pot ser que el codi i les convencions siguin compartides per les dues cultures, la d'origen i la d'arribada, $[\ldots]$ en aquests casos es tracta d'identificar els «universals lúdics» $\mathrm{i}$ aplicar una equivalència formal amb una traducció gairebé literal o, fins i tot, inserir o afegir una explicació dins l'acudit sense perdre l'efecte còmic. El problema ve quan es donen codis diferents i una absència de referents comuns (González Davies 1998: 265).

Els codis diferents, l'absència de referents comuns i, en definitiva, la mancança d'una competència del lector són els principals problemes que troba el lector en la cultura d'arribada i provoca que no puga gaudir de les contínues transgressions a la norma dels personatges que hi intervenen. És per això que 
Alícia, que va representar un dels primers best-sellers de la literatura infantil anglesa $i$ ha esdevingut el llibre clàssic d'aquesta literatura, ha estat un fracàs de públic de les traduccions que es realitzaren i es distribuïren en cultures com la catalana. De fet ara, és un llibre més conegut pels estudiants de traducció de les universitats en transformar-se en un text imprescindible del seu treball que pels lectors als quals anava dirigit.

L'obra fou traduïda al català el 1927 per Josep Carner (1884-1970) i amb il-lustracions de Lola Anglada (1893-1984) sota el títol Alícia en terra de meravelles. La traducció de Carner adapta els jocs lingüístics i les paròdies literàries proposades a l'original: Carner utilitza com a hipotextos per realitzar les paròdies literàries, textos de Mossèn Cinto Verdaguer, Guimerà o Maragall amb un intent d'aproximar-se al lector català. També fou aquesta l'opció de Lola Anglada que transforma la cuina de la Duquessa amb tomata, albergínies i una botija, la baralla en una espanyola i la casa on passen les aventures en una masia.

Ja hem dit que un exemple de la dificultat de traduir una obra com aquesta és el tema complex de l'humor, tant diferent en èpoques i cultures diferents. I adopta noves dimensions quan l'obra té com a lectors els infants perquè els temes humorístics poden cristal-litzar-s'hi tant per mitjans lingüístics com extralingüístics, és a dir, l'humor en una obra pot ser verbal o visual, com González Davies (1998: 263) analitza. Aquesta doble opció és la que hi ha a l'obra de Carroll amb la il-lustració de Tenniel (qui cal recordar era un dibuixant satíric consagrat que col-laborava amb la revista Punch) i que Lola Anglada vol mantenir amb resultats diferents:

L'objectiu de Carner era anostrar el llibre, aconseguir que fos familiar per al lector català, i això es veu també clarament als dibuixos de Lola Anglada. L'efecte lúdic, però, minva. [Amb l'exemple del Capeller] Tennier s'inclina per al vessant de la bogeria, i plasma la sensació de malson, d'humor negre que envolta la narració amb la caricatura grotesca: no porta sabates, va desmanegat, porta el menjar i el beure a la mà, sembla a punt de caure, $i$ va vestit de pallasso. En canvi, Lola Anglada dulcifica el personatge, el fa distingit, gens caricaturitzat i més anostrat (González Davies 1998: 263).

Tot i l'encert de la traducció, Alícia no arriba a fer-se popular entre els infants catalans fins la versió cinematogràfica de Walt Disney, justament perquè el lector proposat al text necessita d'una enciclopèdia cultural que no tenia el català i en la versió cinematogràfica anestesia aquelles parts del text que restringeixen el lector i n'amplia la resta. Amb tot, això no lleva perquè guanyés importància en els circuits adults. Per entendre aquest fenomen és important situar la traducció d'Alicia en el context històric (González Davies 2002: 185):

La traducció tenia categoria de creació i afavoria la descoberta de l'altre i una incorporació cultural de primer ordre que duien a terme els autors consagrats de l'època amb plena consciència de la seva tasca, i explicaven els seus objectius a les introduccions i prefacis de les seves traduccions. 
El mateix Maragall, traductor de Goethe, Novalis, Nietzsche o Wagner, en l'article «Traducciones», parla del paper que les traduccions representaven per a una llengua com la catalana que havia quedat, d'ençà del segle XV, «sin cultivo literario y abandonada, por tanto, al rebajamiento de los usos vulgares», que requeria d'una acció doble:

Purgarse de toda la miseria que ha criado en su encierro, para reintegrarse en su antigua pureza; y compenetrarse con las otras lenguas que la civilización ha ido trabajando, para alternar con ellas en la expresión que el espíritu moderno necesita (Maragall, 1901: 165-166, citat per Male 2007: 80).

Just per aquest plantejament «estratègic», Josep Carner compagina la traducció amb la creació com a poeta i prosista, igual que feien Manent o Riba. Per a Fuster (1985: 309) aquest és un fet habitual en tota la producció editorial i una conseqüència directa de la política propiciada pel Noucentisme:

\begin{abstract}
El Noucentisme, classicitzant, suggereix d'anar a cercar un remei en els clàssics de l'Antiguitat, en els «clàssics» en general. I Riba propugna de suplir el defecte amb una dosi massiva d' «humanitats»: «no amb unes soles humanitats grecollatines, sinó també amb unes novíssimes humanitats que abracessin les irrenunciables adquisicions del «Quatrecents al Noucents».
\end{abstract}

Entre els clàssics ocupaven un lloc important els dirigits a la lectura dels infants $\mathrm{i}$ joves, justament perquè representen el futur i les noves generacions han d'educar-se amb la millor literatura des de la llengua pròpia.

La investigadora González Davies (2002: 185) analitza la importància cabdal que guanya la traducció en aquest moment històric i proposa d'entendre-la des de dos paràmetres: i) la visibilitat del traductor és gran perquè és un autor consagrat que adapta el text original segons el seu objectiu polític o ideològic; de fet, l'Alice de Carroll es transforma en l'Alicia de Carner i ii) la traducció s'entén com la construcció de ponts entre la cultura catalana i la del text traduït.

Si en el període anterior de la literatura catalana els textos traduïts van ser l'obra de Perrault, en l'època que analitzem es tradueixen els contes populars dels Grimm i les faules de La Fontaine; les novel-les del XIX publicades a Anglaterra i França com Ivanhoe de Walter Scott, La volta al món en 80 dies o L'illa misteriosa de Jules Verne, Les aventures de Tom Sawyer de Mark Twain, Robinson Crusoe de Defoe, El llibre de la jungla de Kipling, Oliver Twist de Dickens o L'illa del Tresor d'Stevenson.

Tant la selecció com el tipus de traducció o el circuit literari que les obres creen en la cultura d'arribada és conseqüència d'un disseny polític, cultural i editorial previ. De fet, tot i que la traducció és una més de les accions programades des del moviment institucional per vitalitzar el llibre infantil, totes les traduccions publicades mantenen una relació de transposició lingüística de la 
llengua original al català, sense cap tipus de transformació que l'adeqüe a un lector infantil. I així es fa constar a la coberta, com en la traducció de l'obra de Walter Scott El talismà que diu: «Traducció directa de l'original per Carles Capdevila».

Rovira (1976) i Valriu (1994) destaquen que durant els primers anys del segle va ser fonamental el treball de les institucions en un triple vessant: la creació, la difusió i el consum. Aquestes accions són la conseqüència de la idea de la «Catalunya ideal» i al mateix temps l'instrument per ajudar a preparar el futur. Els beneficis són notables, com descriu Rovira (1976), el llibre arriba, tant pel seu contingut com per la seua presentació, a una qualitat mai no assolida. En aquest context cal situar i analitzar la traducció que Carner fa d'Alicia:

Following the line set by the German Romantics, language was believed to be - and still is - the main signo d identity, and translation was considered as the best means to support the process of creating a national literature. Its main beliefs ans aims were to open Catalonia to the world and update its literature and language, mainly through translation [...]. The translator was deemed, in Montoliu's words, «an educator of the masses» (González Davies 2003: 13).

Les dades de les anàlisis de Ferran Toutain (1997) van en la mateixa línia en parlar de la traducció i dels models estilístics. L'autor investiga com les versions fetes pels traductors que segueixen un model noucentista, com el cas de Carner, s'expliquen més bé per la idea d'integració en un sistema de llengua d'arribada que no per la relació amb els textos de partida. Per tant, com hem analitzat, és en aquest paradigma que interpretem la traducció d'Alicia.

\section{GEORGE'S MARVELLOUS MEDICINE. LECTURA I CIRCUIT ESCOLAR}

El cas de George's marvellous medicine (1981) és ben diferent, cal fer una reconstrucció del context polític, cultural i educatiu per entendre com la traducció de l'obra George's marvellous medicine entra en un circuit diferent de l'anterior, ens referim al circuit de la lectura captiva per l'escola a través del mediador i la selecció de lectures recomanades. Cal recordar que a consequiència de la dictadura franquista, la lectura a Espanya en general i la lectura en èuscara, gallec i català en particular funciona quasi exclusivament en l'àmbit escolar. La dècada dels seixanta és un moment de transició perquè les circumstàncies socials i polítiques possibiliten la connexió i consolidació d'una edició pensada per als infants a partir del treball que realitzaren petits grups d'ensenyants, editors i escriptors des de l'exili o des de l'interior del país.

Les persones que havien participat durant la república i la guerra civil en la producció de llibre per a infants es relacionen amb les noves generacions, i 
aquest vincle que estableixen funciona com un imant entre l'experiència del passat i els projectes del present. Es construeix un pont entre el que s'havia fet abans de la guerra i les accions de la dècada dels seixanta, d'aquesta manera s'evita partir de zero i oblidar o soterrar els aprenentatges i el treball anterior.

De manera similar, la relació d'aprenentatge que s'estableix amb el passat, també es dóna amb els moviments pedagògics i literaris més actius que revitalitzen la cultura i el món del llibre per a infants. Itàlia i França són un lloc on mirar i aprendre quin és el model d'escola, de llibre i de lectura més adequat per als infants catalans.

Així doncs, els grups que comencen a treballar en la creació d'un circuit lector busquen el diàleg amb els exiliats, amb les generacions de la república i amb els col-lectius de mestres i d'editors d'Europa. D'aquesta manera, es construeixen uns fonaments poderosos que van permetre recuperar i aprendre del treball realitzat anteriorment i de les experiències coetànies que són capdavanteres a França i Itàlia.

Aquests fets, entre d'altres, van propiciar els canvis d'aquesta dècada i que Rovira (1988: 463) resumeix en els següents: i) la inquietud d'un sector del món intel-lectual pel problema de la lectura infantil, com ho demostra la conferència d'Artur Martorell pronunciada el 1960, l'article «Una edat sense llibres o una literatura sense futur» de Joan Triadú (1962) a la revista Serra d'Or o el treball realitzat a les escoles Talitha i Costa i Llobera; ii) la publicació del primer número de la revista Cavall Fort l'1 de desembre de 1961; iii) la creació de l'editorial La Galera l'any 1963 i la convocatòria del Premi Folch i Torres per a llibres infantils i el Joaquim Ruyra per a adolescents que donen a conèixer i promocionen obres i autors; iv) la traducció a partir de 1961 d'alguns dels llibres d'imatges més famosos internacionalment i vii) el moviment d'escola activa preparat des dels anys cinquanta per una generació de professionals de mestres que intenten crear a les escoles uns lectors de llibres infantils en llengua catalana.

Les dades claus que marquen el punt de partida són l'any 1961, amb la publicació del primer número de la revista Cavall Fort i el 1963 data en què l'editorial La Galera comença a publicar els primers llibres per a infants (Lluch 2013: §5). Ara bé, és important ressenyar un fet anterior a les dates apuntades per Rovira: en el mes juny de 1960 se celebra a Barcelona la I Semana del Libro Infantil y Juvenil, que va ser inaugurada amb una conferència d'Artur Martorell en la qual traça la ruta ideològica que guiarà la construcció d'un circuit literari català per a infants i joves. Martorell remarca l'augment de la producció i de les vendes del llibre infantil a Europa determinat per les noves formes i els nous temes que l'han fet més atractiu: l'aparició cada any al món de 9.000 títols nous i la necessitat que tots els llibres han de tenir una dignitat, bellesa, puresa de concepció $\mathrm{i}$ d'estil és un dels temes centrals de la seua conferència i porta l'atenció a la necessitat de donar a cada edat un tipus de llibre adequat, de diferenciar entre llibre d'esplai i escolar. 
Al llarg de la conferència, la reivindicació de la qualitat estètica del llenguatge, dels temes, de les il-lustracions i en general del llibre per a infants és una constant (Martorell 1987: 7):

El valor educatiu de la lectura en ella mateixa, com a coneixement instrumental indispensable per al desenvolupament de les facultats del llenguatge i de judici del nen i per tal d'obrir la seva ment al coneixement i a l'amor del món que el volta en tots els seus aspectes -formal, humà i fenomenològic; i, d'una altra part, el valor importantíssim del llibre, també en ell mateix, com a mitjà objectiu d'una alta influència educativa en la formació del caràcter, del llenguatge, de l'esperit cívic, de l'ètica personal, del gust estètic i de l'espiritualitat; aspectes, tots ells, en els quals la qualitat del llibre i les seves característiques de fons i de forma influeixen poderosament $i$ poden exercir $i$ en realitat exerceixen un paper de gran importància. Paper que pot resultar positiu o negatiu, beneficiós o nefast, segons quines siguin aquestes característiques.

Un any més tard, com analitza exhaustivament Bassa (1994: 44-51), la revista Serra d'Or publica una sèrie de cartes al director i d'articles d'opinió que reclamen una literatura adreçada als infants i joves. L'article que va tenir un major ressò va ser escrit per Joan Triadú el 1962 (VII/VIII) titulat «Una generació sense llibres, una literatura sense futur» en referència a «Una generació sense novel-la» la conferència de 1925 de Carles Riba:

Si dos poetes van parlar un dia, amb raó, d'una generació sense novellla, avui hi ha una joventut que testimonieja de no haver tingut llibres durant els anys més aprofitables per a adquirir uns hàbits de lectura (Triadú 1962: 34).

Al llarg de l'article, Triadú parla de la mancança de llibres en català per a infants i joves i de com els llibres són necessaris per als anys d'aprenentatge literari: «Avui, durant aquestes dècades, de cada cent possibles lectors en perdem noranta-nou», i després de fer un repàs sobre quines van estar les lectures, en català, de la seua joventut demana que els editors publiquen llibres per a infants i adolescent per fer-los lectors en català.

Aquestes opinions són refermades per les dades de l'enquesta de 1960 dels «Amigos de la Cultura y del Libro» als escolars barcelonins de 8 a 14 anys des de l'Instituto Nacional del Libro Español de Barcelona i publicada el 1961. Els resultats són força eloqüents i retraten molt bé la situació comentada per Triadú ja que no hi havia llibres en un $41 \%$ de les cases dels nens enquestats i només els regalaven d'1 a 2 llibres a l'any. A més, a la pregunta «¿Cuál es el primer libro que has leído?» responen amb el nom d'alguna cartilla; un $8 \%$ dels nens enquestats citava El Quijote com el primer llibre que havia llegit o bé el que li havia agradat més, o el que volia llegir o que li regalaren. Menys d'un 2\% dels nens citava un títol català.

Per tant, en l'inici de la dècada dels seixanta coincideixen factors importants com ara i) la voluntat de la família, dels ensenyants i dels editors de crear, editar, recomanar i comprar llibres de qualitat; ii) la demanda social d'una lectura d'excel-lència per als infants, iii) l'opinió compartida sobre la lectura com 
un instrument necessari per educar una nova generació de nens i la voluntat d'educar-los d'una forma diferent sota els pressupòsits de la pedagogia d'una escola activa i, el que és més important. I sobretot que hi havia unes condicions socials i polítiques que permeten aquests canvis.

\subsection{La selecció captiva de la lectura recomendada}

Els setanta inicien dos fenòmens nous en la lectura per a infants en català: la publicació del primer best-seller, Mecanoscrit del segon origen de Manuel de Pedrolo, editat el 1974 a Edicions 62 i la recomanació de lectures a l'escola que crea un circuit singular i diferenciat de l'adult. Castellet recorda el primer fet de la manera següent (Vila-Sanjuan 2003: 258): «Lo leí y le sugerí publicarlo en una colección para adolescentes que teníamos entonces. El Trapezi. Estuvo de acuerdo». D'aquesta manera el llibre es transforma en el de més èxit de l'editorial.

Mecanoscrit... inicia un circuit de lectura diferent on la figura del mediador és la fonamental mentre que el lector queda relegat i adscrit a les decisions, consells o compres del docent, el familiar o un gestor. Com a conseqüència, la comunicació literària que s'estableix en el circuit de lectura escolar entre els participants difereix en alguns aspectes amb la que proposa la literatura adulta (Lluch 2003: cap. 1). El circuit escolar divideix els actors en dues esferes que creen una forta dissimetria: per una part, els productors del text que en un sentit ampli són els autors, els mediadors del text (editors, institucions, escola...) i els primers receptors (mestres i pares). I per una altra, el segon receptor: el lector real del text, el petit o el jove. Aquesta comunicació la representàvem en el gràfic (Lluch 2003):

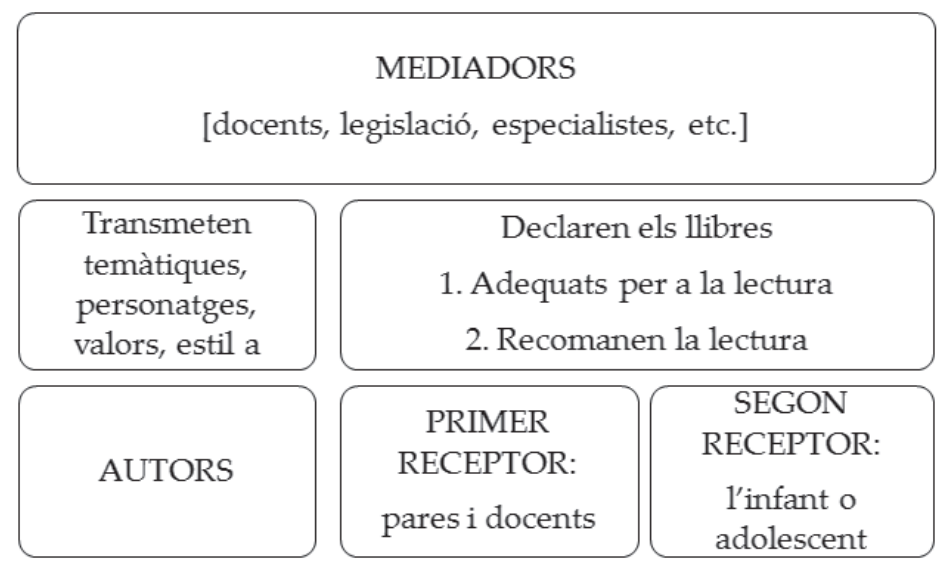

En aquest circuit, la lectura de creació per a infants i joves és sinònim del relat que se situa en la frontera de l'edifici literari, al costat dels relats de tradició oral, de la paraliteratura i dels textos que s'escriuen pensant en les característiques específiques del lector concret que els consumirà (Lluch 2010). 
L'editor de llibres per a infants, aconsellat pels mediadors, proposa un tipus d'obra a l'autor amb unes característiques discursives marcades per la tradició, la didàctica, la ideologia, etc. La característica compartida per la majoria d'aquestes lectures té a veure amb la repetició en els tres àmbits de la comunicació literària: en la producció (per exemple, motivades per les característiques de les col-leccions o per la influència dels textos ideològics o dels documents legislatius), en els elements paratextuals (lligats al disseny i característiques de la col-lecció) i en la textualització (per exemple, tipus d'estructura o personatges) (veg. Díaz 2006 i Lluch 2009).

Just en aquest circuit literari hem d'analitzar George's marvellous medicine (1981). La traducció d'Albert Folch i Folch el 1986 arriba ja a un circuit lector consolidat: una indústria editorial que publica llibres per a infants i joves de qualsevol indret del món, una escola preparada i uns mestres capdavanters i informats. Però un circuit, com hem explicat abans, on la lectura no s'adreça directament al lector: és el mediador qui tria, qui decideix els criteris de selecció. És el que anomenem una lectura mediatitzada per la recomanació.

Oriol Izquierdo (2010: 99), en descriure les característiques del qüestionari sobre les obres de referència per a la tradició literària catalana que posa en marxa la Institució de les Lletres Catalanes, expressa amb aquestes paraules el lloc que ocupa la literatura per a infants en català respecte del cànon:

\begin{abstract}
Lleugerament a part és el cas de la literatura infantil i juvenil. Ha estat tradicionalment un dels «subgèneres» més potents en la nostra cultura, ja abans de Folch i Torres, però alhora aquest prefix acostuma a tenir connotacions despectives. No dubtem que alguns enquestats haurien incorporat aquestes obres naturalment en la resta de punts, però els hem volgut donar un tractament específic per convidar tots els participants a prendre consciència de la consideració que tenen envers les obres literàries infantils i juvenils.
\end{abstract}

És a dir, el qüestionari queda dividit en set parts (una primera de resposta espontània, i sis de resposta guiada) que són: 1) Clàssics de la literatura catalana, 2) Literatura catalana actual, 3) Traducció, 4) Literatura i gènere, 5) Literatura infantil i juvenil i 6) Literatura i educació. Per tant, se li atorga un estatus similar a traducció, gènere o educació i impossibilita que algunes obres o autors apareguen com a clàssics o com a literatura catalana.

De fet, les anàlisis sobre els llibres que es recomanen en el circuit escolar mostren majoritàriament uns relats amb característiques pròximes a la paraliteratura (Boyer 1992, Couegnas 1992, Lluch 2003 i 2009). Jesús Díaz (2006) aporta un exemple en analitzar els personatges dels relats llegits en el circuit escolar en espanyol i les conclusions (perfectament transferibles al mercat en català) eren les següents:

a. Les temàtiques majoritàries són la drogoaddicció, l'anorexia, la violència del carrer, els abusos sexuals, el fracàs escolar... Majoritàriament, són conflictes específics i centrats en la població juvenil. 
b. Són relats que majoritàriament representen un procés de maduració marcats per una finalitat didàctica relacionada amb la inserció, l'acceptació o les propostes de models de vida.

c. Els processos de maduració no tenen a veure amb la supervivència en un món hostil sinó que es relaciona amb la conquesta de l'autoestima com a premi a l'èxit acadèmic, social o de l'amor.

d. Els antagonistes poden ser adults (professors o especuladors) o altres joves com els estudiants assetjador. Els auxiliars poden tenir un caràcter màgic i quan són reals els personatges que tenen aquest paper són els mestres, avis o altres companys.

\subsection{L'obra de Dahl}

Tot i la presència de Roald Dahl en el circuit escolar, és un dels pocs autors que s'allunya de la línia descrita per Díaz (2006) perquè més que escriure per al mediador s'adreça al lector real: el nen. La seua obra representa individus amb conductes diferents de les socialment establertes: són diferents en referència al que la tradició ha etiquetat com a conductes pròpies per ser divulgades en productes dirigits als nens. Però encara que ha estat considerat subversiu i, al principi, condemnat per alguns mediadors, ha resultat un dels autors amb més èxit del segle XX. El tractament dels personatges, la condemna del nen malcriat, la recuperació de personatges que representen el mal, la representació d'un món on la solitud i el dolor estan present però tractats des de l'humor o el sarcasme és una mostra de com es poden escriure bons relats per als infants.

L'anàlisi dels relats de Dahl que funcionen en el circuit escolar de l'educació secundària ( $\$ 7$. Corpus d'anàlisi) mostra la caracterització de la seua obra. La construcció narratològica de Dahl respon al model habitual en el món de la literatura per a infants i joves: els fets s'organitzen en cinc seqüències narratives i segueixen una progressió temporal lineal. Però la diferència rau en la darrera seqüència; de fet, una de les característiques més notables de Roald Dahl és el final que escull per a les històries, ben allunyats del model tradicional. Per exemple, a Matilda (1988) la protagonista decideix no tornar amb els seus pares biològics i quedar-se amb la mestra, el protagonista convertit en ratolí a Les bruixes (1983) decideix no buscar un remei per transformar-se en nen i continuar com a ratolí per morir alhora de l'àvia i a La meravellosa medicina d'En Jordi (1981) l'àvia desapareix i la mare diu: «Bé, suposo que, en realitat, més val així. Resultava una mica molesto tenir-la a casa, veritat?».

Els seus relats els protagonitzen personatges habituals de la literatura infantil però els presenta amb unes funcions diferents: els personatges adults habitualment realitzen funcions d'antagonistes, sobretot aquells que tenen poder sobre els nens com els pares, els mestres i les àvies. Aquesta proposta narrativa destrueix la representació més clàssica i tradicional de la literatura per a infants: la 
família com a personatge col-lectiu que tradicionalment ha representat funcions positives, de suport al protagonista infantil i amb qui estableix relacions de calidesa o ofereix pautes de comportament i de construcció d'ideologia. Però en l'obra de Dahl trobem mestres com la senyora Trunchbull, pares com els de Matilda o com el personatge de l'àvia de Jordi, són personatges estàtics i plans i encara ens sorprenen. Ara bé, la sorpresa no rau en l'evolució personal del personatge producte dels fets que li esdevenen durant el relat sinó en l'actitud que mantenen, lluny de la ideologia políticament correcta tan habitual en la literatura per a infants. Per exemple: a Matilda els pares defensen el menjar dolent o l'addicció a la televisió, el pare de Jordi malparla de l'àvia i la menysprea, la mare la ignora i l'avia queda lluny de les dolces iaies que poblen la lij.

L'altre tret dels relats de Dahl té a veure amb la funció de les il-lustracions que sempre són de l'autor Quentin Blake (1932). El diàleg que el llenguatge visual i escrit creen augmenta el to humorístic i fins i tot macabre del text amb el qual estableix tres tipus principals de relacions: unes vegades reforça la descripció, com en el cas de les transformacions de l'àvia [Il-lustració 1]; d'altres, reprodueix un sequiència narrativa com en la transformació final de l'àvia a $L a$ meravellosa medicina..., o quan mostra la transformació de la senyora Culdolla [Il-lustració 2] o supleix el text quan les il-lustracions apareixen a continuació d'uns punts suspensius com en el cas de l'aspecte final que té el porc una vegada ha pres la medicina màgica d'En Jordi i en comptes de descriure el seu aspecte diu: «Al final, tenia aquest aspecte...» [Il-lustració 3].

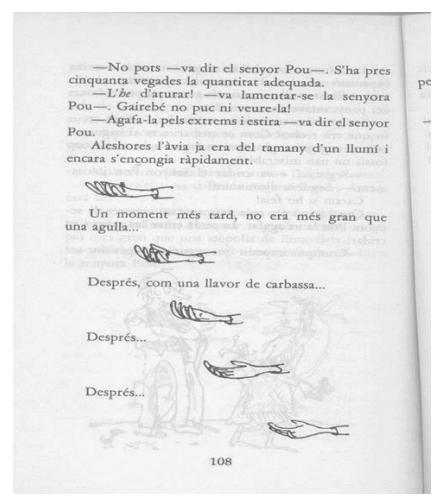

[Il-lustració 1]

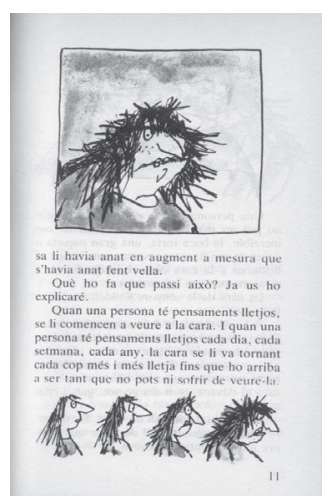

[Il-lustració 2]

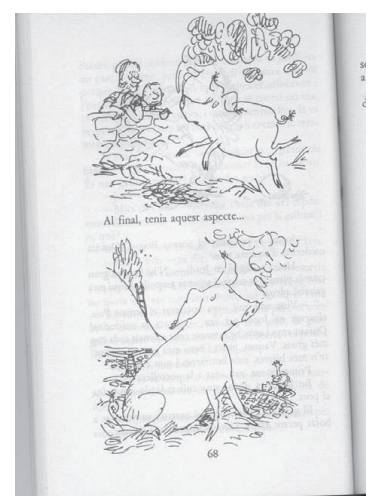

[Il-lustració 3]

La traducció de La meravellosa medicina d'En Jordi arriba quinze anys després d'inaugurar el circuit escolar de lectura en català i una mostra de com va ser acollida la trobem en la història de Lola Casas (2009) que pot representar la d'altres mestres quan descobreixen l'obra de Dahl:

La meravellosa medicina d'En Jordi em provocà un considerable mal d'estómac! Em va agradar, era divertidíssima... Però, cal dir que em va descol-locar. Aquell conte era bestial! Aquella iaia era un monstre! En Jordi, 
el protagonista... també era una mica monstre! I la reacció del pare, de la família en general, de quedar-se tan amples quan la malvada iaia desapareix (per culpa seva, així sí)... ¿No traspuava una total manca d'ètica? Vaig decidir deixar de banda els meus perjudicis i donar el llibre als nens sense dir ni piu, ni de bo ni de dolent, permeten que fossin ells els que jutgessin el producte. I van donar el seu veredicte, i un tant per cent elevadíssim va quedar encantat, sense mostrar cap tipus de mala consciència pel comportament dels personatges. A poc a poc els llibres de Dahl van anar entrant a les classes.

\section{HARRY POTTER. LECTURA I MERCAT}

El panorama editorial del segle XX i principi del XXI dibuixa un mapa ben diferent conseqüència de l'èxit de vendes de la saga protagonitzada per Harry Potter (1997-2007). Els llibres protagonitzats per aquest personatge inauguren el fenomen de la venda massiva de llibres a través de l'anomenada compra per impuls, és a dir, un circuit en el qual la lectura es deslocalitza de l'escola per passar al mercat i es lliura de la tutela del docent per passar a la del màrqueting.

La saga de Harry Potter no passarà a formar part del cànon literari juvenil però sí que ocuparà un capítol als estudis de la sociologia de la lectura. Els set llibres escrits per Rowling van aconseguir donar el salt qualitatiu que les lectures per a nens i joves havien iniciat anys abans: passar de l'escola (o de la biblioteca) al mercat. A partir de Potter, l'autor i l'editorial inicien una comunicació directament amb el lector i s'alliberen en part de la tutela del mediador que hem descrit abans.

L'èxit de la saga farà que els adolescents compren directament els llibres en anglès (de fet, és la primera vegada que llibres no traduïts es poden comprar en llibreries no especialitzades i que, a més, se situen a les taules de novetats), que els baixen il-legalment d'Internet, els promocionen a través del mòbil i dels fòrums de lectors. I sobretot que s'intensifique la lectura fora del centre escolar.

\subsection{Característiques discursives del relat}

En la nostra anàlisi, considerem el set llibres protagonitzats per Potter com a diferents lliurament d'un mateix relat. L'anàlisi del relat aporta dades per afirmar que ha canviat algunes maneres d'editar, d'escriure i de fer arribar els llibres als lectors. Una vegada analitzats els set llibres (§ 7. Corpus d'anàlisi), podem resumir els trets que el caracteritzen. Per fer-ho partim del terme «univers de ficció» que utilitzàvem a Lluch (2010: 118) en el sentit que el definia Pérez Latorre (2007: 118) quan l'aplica a les sèries audiovisuals:

Una macroestructura narrativa donde caben no una sino múltiples historias posibles. Se compone de un mundo central o de referencia y una serie de mundos posibles que constituirían diversas alternativas narrativas con independencia de si éstas tienen lugar o no en la serie de forma efectiva. 
Més enllà dels nous relats (audiovisuals, jocs, etc.) que l'univers original genera, Rowling construeix un univers de ficció que s'inicia amb el naixement d'un nen que ha de dur a terme una profecia i finalitza amb una prolepsi on ens mostra per fi un món en equilibri.

La història principal està protagonitzada per l'enfrontament entre Harry Potter i Voldemort que representa el de les forces del bé i del mal. Aquest argument principal s'alimenta d'altres històries del present, però també de múltiples analèpsies i prolepsis.

La presència d'històries del passat és contínua i la solució narratològica utilitzada doble: en alguns casos, els personatges conten fets del passat (narració de paraules) però sobretot en els darrers llibres s'opta per una solució més audiovisual: els personatges viatgen al passat i observen què ocorre (narració de fets). Les analèpsies sempre estan associades al coneixement del mal, del personatge de Voldemort que provoca el desequilibri en l'univers de ficció de la saga a través de potenciar el pitjor d'alguns personatges: el racisme, l'odi, la venjança, el temor a l'altre, la falta de llibertat, la tortura o la mort.

De manera similar a las sèries audiovisuals, el primer llibre crea el model estructural que es manté en els següents però amb nous personatges i trames i afegint-hi complexitats discursives. Les marques identificatives més reconegudes són el primer capítol que situa Harry esperant l'inici escolar i el títol sempre construït a partir del nom del protagonista i l'objecte cercat en cada llibre.

Estructuralment, la narració transcorre al llarg d'un curs escolar i, com és habitual, es construeix amb una trama principal (la cerca de l'objecte del títol) i d'altres secundàries, que es mantenen al llarg de diferents llibres per avançar el final i amb ell el desenllaç del conflicte. Cada trama crea nous enigmes d'importància diferent però amb una mateixa finalitat: generar el que Balló (2005) anomena «nostàlgia de futur», és a dir, enyorar el llibre que encara no s'ha publicat, en alguns casos ni està escrit però que el lector vol llegir aviat.

Els personatges es mouen en esferes diferents que interactuen al llarg del relat: nens i adults, el mal i el bé, els tres amics i les famílies, l'escola i la societat, els muggles i els mags... Una forma d'interactuar que segueix les «lleis èpiques» que Axel Olrik (1992: 41-53) observa en les narracions orals.

Des de l'inici del relat el protagonisme recau en Harry i el professor Dumbledore i la professora McGonall el presenten a la primera pàgina com un heroi amb característiques bíbliques: «Serà famós, serà un mite...», diuen quan deixen un Harry bebè a la porta dels seus oncles. A més, hi porta una marca que l'identifica com a heroi. Però a mesura que avança el relat, el protagonisme es comparteix. De manera similar a les sèries coetànies del relat com ara Lost (2004-2010), el protagonisme compartit augmenta a mesura que avancem en els lliuraments fins arribar a l'últim títol en el qual Harry Potter, els seus tres amics i els integrants de l'exèrcit de Dumbledore o els de l'Ordre del 
Fénix es reparteixen el protagonisme. El millor exemple és veure com al final acaben amb Voldemort entre tots a través de la destrucció dels diferents Horricreus: el diari, destruït per Harry; l'anell de Sorvolo, per Dumbledore; el guardapelo de Slytherin, per Ron; la copa de Hufflepuff, per Hermione; la diadema de Ravenclaw, per Crabe i la serp Nagini, per Neville. I l'últim, Harry. D'aquesta manera, el protagonisme d'Harry es dilueix una mica en benefici de la resta de personatges.

Una altra característica dels personatges és l'ambivalència i profunditat que mostren, òbviament, des dels paràmetres de la paraliteratura o del relat popular. Els personatges encara que aparentment semblen plans i estereotipats o concentrats en les esferes del mal i del bé, a mesura que avancem en la saga, guanyen en complexitat i matisos: s'equivoquen, s'enfronten a sentiments negatius com la ira o les ànsies de poder, creixen i dubten, acumulen experiència $i$ amb ella encerts i errors. Dumbledore, Snape o el mateix Harry són bones mostres d'aquesta ambivalència o el final de Snape o els Marfoy salvats per l'amor als amics i a la família.

Els personatges més joves creixen a mesura que viuen entre les pàgines dels llibres per contra els adults mantenen unes característiques més constants en el moment que el relat els situa. Ara bé, el lector rep informació del seu passat, del creixement, dels canvis, de les febleses i fortaleses a partir de les analèpsies que informen de Dumbledore, Snape, dels pares de Potter i sobretot Voldemort.

L'administració de la informació és un punt fonamental en l'èxit de la saga. El fet que Harry Potter desconega el funcionamient del món màgic obliga que, a través dels diàlegs, haja de rebre continuament informació que l'ajuda a reconèixer fets, enigmes, comportaments o fer memòria històrica. Per crear suspens el personatge se situa en el mateix punt d'ignorància que el lector. El món de la màgia és tant aliè a Harry com per al lector, com a consequiència, la ignorància del protagonista és un recurs retòric perfecte perquè exigeix l'ús metalingüístic del diàleg per explicar (a Harry però sobretot al lector) el funcionament del món possible de la saga.

Al llarg del set llibres bona part dels relats que conformen l'imaginari infantil hi són presents, com a relat representatiu de la cultura popular és un bon exemple de narració construïda des de la hibridació de gèneres i amb múltiples relacions intertextuals amb gèneres, autors i llibres concrets. Però no solament escrits perquè, de fet, a mesura que la sèrie avança les relacions intertextuals amb els gèneres audiovisuals augmenten. Per exemple:

- les narracions d'internats (la saga escrita per Enid Blyron Torres de Malory): la vida a l'escola, la convivència amb els professors o les relacions entre els estudiants;

- les novel-la de colles (les col-leccions d'Enid Blyton com Els cinc, Els set...): nens llestos amb enigmes complexos, enfrontaments de nens a adults,tipologia de cada nen en la colla, etc. 
- les novel-les de fantasia èpica (Els senyor dels anells, Les cròniques de Nàrnia...): tipologia de personatges fantàstics, elements màgics, objectius i tasques o les lleis de relacions socials;

- les novel-la d'aventures, d'enigma i de l'heroi;

- la recuperació de personatges clàssics de les novel-les fantàstiques i de la mitologia i de les seues característiques: gegants, dracs, unicorni,etc.

- la narrativa actual clàssica com l'escrita per Roald Dahl;

- el cine d'adolescents, sobretot, el de terror, el gore, el de colles d'adolescents, etc.

La influència de la narració audiovisual va més enllà de les relacions intertextuals i arriba fins a la forma d'escriptura creant una narració visual en la qual es crea una sensació confusa entre el temps narrat i el temps de lectura fins al punt que l'estil narratiu crea la sensació de mirar més que llegir, un estil que ja es consolida a The Hunger Games. És a dir, a la manera d'altres narracions recents d'èxit, el diàleg crea un ritme intern ràpid que suscita un major interès en el lector en fer avançar l'acció en «temps real» perquè explica els fets a través dels torns de paraules que narren en primera persona, en present i des del lloc dels fets el que esdevé i confereixen a la narració una rapidesa característica que agrada a un lector acostumat al ritme narratiu del relat audiovisual.

\subsection{Harry Potter en el circuit en català}

Quan la saga arriba al circuit de lectura en català el que ocorre és que molts lectors no esperen la traducció, compren el llibre directament en anglès per aquesta «nostalgia de futur» de la qual parlàvem adés. Però també ocorre un altre fet: els joves lectors creen un espai web compartit i entre diferents adolescents inicien la traducció conjunta de l'obra per oferir-la de manera gratuïta als lectors de la forma més ràpida possible. Però l'acció dura poc perquè l'editorial prohibeix la pàgina. D'aquesta manera naix un nou lector, el que (Lluch 2010) batejàrem com a un nou lector per a un nou segle.

Des de fa uns 15 anys, hi ha al mercat una sèrie de llibres pensats o dissenyats per complaure un lector jove crescut amb els relats audiovisuals dels jocs d'ordinador o de les sèries creades originalment per a la televisió. Escrits per autors que es promocionen com els cantants o els actors i els llançaments dels quals s'acompanyen de crits d'alegria dels fans-lectors ocupant pàgines de la premsa no marcada per la festivitat nadalenca o les vacances escolars. És un lector diferent que tria la lectura, que s'acosta al llibre sense el consell de cap mediador i que, en alguns casos, no li importa la llengua de lectura. 


\section{CONCLUSIÓ: ELS CIRCUITS LECTORS EN EL MERCAT EN CATALÀ}

La conclusió principal que deriva de l'anàlisi realitzada és la següent: des dels inicis del segle XX als inicis del XXI, la traducció dels principals relats de la literatura anglesa funcionen en tres circuits literaris que mostren l'evolució del la lectura per a infants i joves en català. Un primer circuit lligat a l'administració política de principis del segle passat on un autor consagrat adapta el text original segons el seu objectiu polític o ideològic i realitza la traducció amb la finalitat d'integrar la nova obra en un sistema de llengua d'arribada i no per la relació amb els textos de partida. L'escenari canvia en la dècada dels seixanta sobretot per la voluntat de la família, dels ensenyants i dels editors de crear, editar, recomanar i comprar llibres de qualitat. Hi ha una demanda social d'una lectura d'excel-lència per als infants que passa, quasi en exclusiva, per l'escola. En anys posteriors, aquesta demanda crea un segon circuit de lectura, paral-lel al circuit adreçat a l'adult, amb un canvi d'actors que acaba en una selecció de lectures captiva per l'escola a través del mediador. Finalment, el segle XXI inaugura en el mercat en català una lectura mediatitzada pel mercat. Els tres circuits els podem representar en el mapa conceptual següent:

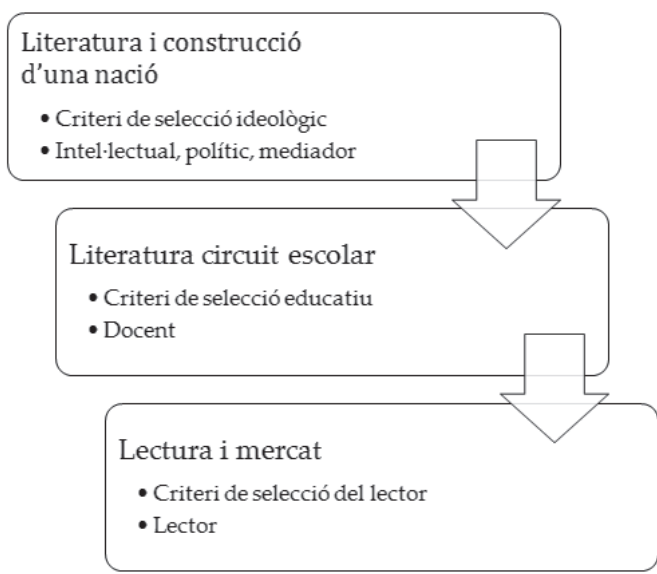

Per tant, en aquest recorregut, hem descrit el pas d'una lectura controlada pels agents polítics, al control escolar per acabar en el del mercat. Cada vegada més el mercat del llibre per a infants i, sobretot, per a adolescents se sembla més al dels adults. Com afirma Gómez-Escalonilla (2007: 167) en l'estudi sobre les polítiques del llibre:

Existe un mercado que favorece el éxito de la producción más comercial, apoyándola no solamente con una distribución eficaz sino también especialmente con agresivas campañas de promoción y publicidad excluyendo la cultura especializada o minoritaria. 
Una conseqüència d'aquesta, relativament nova, forma d'entendre la lectura es resumeix en la valoració que la mateixa autora fa de la lectura adulta i que trobem vàlida per al nostre corpus d'anàlisi (Gómez-Escalonilla 2007: 173):

El problema no es sólo que se lee poco, sino que se lee poco de muy poco, y ese poco no es precisamente, lo mejor. Sucede que la dinámica del best-seller está contribuyendo a un cambio en las motivaciones de la actividad lectora ya que si tradicionalmente el objetivo de la lectura fue la instrucción y el conocimiento, amén del propio deleite, ahora se valora mucho más la lectura de evasión, lista para llenar el tiempo de ocio.

El relat hereu de Harry Potter, The Hunger Games, és un bon exemple d'aquest nova lectura. Són les anomenades «lectures per impuls» que no segueixen el sistema anterior perquè no estan pensades per al circuit escolar sinó per al mercat i se situen al costat dels llibres dirigits a un públic no marcat i dels objectes de consum cultural o d'oci dirigits al mateix perfil consumidor: el jove. Com a conseqüència de la deslocalització del llibre de l'escola, el sistema literari anterior reestructura les competències dels antics actors de manera que l'anomenat «mercat» ara és l'actor principal.

Però el canvi no té a veure només amb el circuit de lectura, també amb el procés de traducció perquè tot i que els llibres traduïts en l'actualitat estan escrits en anglès no provenen d'una cultura o d'una tradició; a la manera dels blockbusters (Lluch 2010: 111) es creen en anglès per una qüestió de costos: un mateix producte arriba a més compradors. Però quan arriben al mercat en català o en espanyol, ja no troben un circuit que particularitza la lectura, un circuit que acull l'obra i la fa seua. A la manera dels dibuixos animats que s'ofereixen els mateixos en qualsevol llengua del món o en qualsevol cultura, aquests relats són traduïts ràpidament per ser llegits de manera ràpida, per aprofitar el moment de venda i són devorats ràpidament. Ja no pertanyen a cap cultura, no provenen de cap tradició.

\section{CORPUS D’ANÀLISI}

Les referències bibliogràtiques de les obres que formen part del corpus d'anàlisi apareixen encapçalades per la data de la primera edició en català, a continuació el títol en català i entre parèntesi el títol original en anglès i la data de la primera edició.

Obra de Lewis Carrol analitzada:

1927. Alicia en terra de meravelles, Barcelona, Editorial Juventud (Alice's d'Adventures in Wonderland, 1865). 
Obra de Roald Dahl analitzada ${ }^{1}$ :

1985. Charlie i la fàbrica de xocolata, Barcelona, Edicions de La Magrana (Charlie and the chocolate factory, 1964).

1986. La meravellosa medicina d'en Jordi, Barcelona, Editorial Empúries (George's marvelous medicine, 1981).

1986. Les bruixes, Barcelona, Editorial Empúries (The witches, 1983).

1987. Charlie i el gran ascensor de vidre, Barcelona, Edicions de La Magrana (Charlie and the great glass elevator, 1973).

1987. El Gran Amic Gegant, Barcelona, Edicions de La Magrana (The BFG, 1982).

1989. James i el préssec gegant, Barcelona, Edicions de La Magrana (James and the Giant Peach, 1961).

1988. Els Culdolla, Barcelona, Edicions de La Magrana (The Twits, 1980).

1988. Matilda, Barcelona, Editorial Empúries (Matilda, 1988).

1989. Danny el campió del món (Danny the champion of the world, 1975).

1991. Agu Trot, Barcelona, Editorial Empúries (Esio Trot, 1990).

Obra de J.K. Rowling:

1999. Harry Potter i la pedra filosofal (Harry Potter and the Philosopher's Stone, 1997).

1999. Harry Potter i la cambra secreta (Harry Potter and the Chamber of Secrets, 1998).

2000. Harry Potter i el presoner d'Azkaban (Harry Potter and the Prisoner of Azkaban, 1999).

2001. Harry Potter i el Calze de Foc (Harry Potter and the Goblet of Fire, 2000).

2004. Harry Potter i l'Ordre del Fennix (Harry Potter and the Order of the Phoenix, 2003).

2006. Harry Potter i el misteri del prince (Harry Potter and the Half-Blood Prince, 2005).

2008. Harry Potter $i$ les relíquies de la mort (Harry Potter and the Deathly Hallows, 2007). català.

1 Vull donar les gràcies a Josep Maria Aloy per facilitar-me les dades sobre les edicions al 


\section{REFERÈNCIES BIBLIOGRÀFIQUES}

Balló, J. + Pérez, X. (2005) Jo ja he estat aquí: ficcions de la repetició, Barcelona, Empúries.

Bassa, R. (1994) Literatura infantil catalana i educació (1939-1985), Palma de Mallorca, Editorial Moll.

Bobes Naves, M. (1992) El diálogo. Estudio pragmático, lingüístico y literario, Madrid, Editorial Gredos.

Boyer, A. (1992) La paralittérature, Paris, Presses Universitaires de France.

Casas, L. (2009) «Sobre Roald Dahl. Amb enllaços», http://www.lolacasas.cat/

Cendan Pazos, F. (1986) Medio siglo de libros infantiles y juveniles en España (1935-1985), Salamanca, Fundación Sánchez Ruipérez.

Couegnas, D. (1992) Introduction a la paralitterature, París, Editions du Seuil.

Chartier, R. (1993) Libros, lecturas y lectores en la Edad Moderna, Madrid, Alianza Editorial.

Chartier, R. (2000) Las revoluciones de la cultura escrita, Barcelona, Gedisa, 1997.

Díaz Armas, J. (2006) «Personajes de la literatura juvenil: cambio y maduración», en Sotomayor, V. (ed.) Personajes y temáticas en la literatura juvenil, Madrid, MEC, pp. 73-98.

Escarpit, R. (1968) La revolución del libro, Madrid, Alianza Editorial.

Escarpit, R. (1971) Sociología de la literatura, Barcelona, Oikos-Tau.

Escolar, H. (1988) Historia del libro, Madrid, Fundación Germán Sánchez Ruipérez.

Fuster, J. (1985) Literatura Catalana Contemporània, Barcelona, Curial.

Fuster, J. (1992) L'aventura del llibre català, Barcelona, Empúries.

Gélis, J. (1985) «La individualización del niño», Historia de la vida privada, volum 3, Madrid, Taurus.

Gómez-Escalonilla, G. (2007) «Políticas del libro. Análisis y propuestas», en Álvarez Monzoncillo et alii Alternativas de política cultural. Las industrias culturales en las redes digitales, Barcelona, Gedisa, pp. 165-206.

González Davies, M. (1998) «Traduint l'impossible: aspectes lúdics a Alice in Wonderland», in Messeguer, Ll. i Villanueva, M. (eds.) Intertextualitat $i$ recepció, Castelló, Universitat Jaume I, pp. 259-271.

González Davies, M. (2003) «Translating Children's Literature in a Bilingual Context: Alice in Catalan», The Knight Letter, 2 (70), 12-16, Princeton, the Lewis Carroll Society of North America. 
Izquierdo, O. (2010) «Les raons d'un qüestionari», Cultura. El cànon literari $i$ la transmissió de la tradició, 6, 86-103, Barcelona, Generalitat de Catalunya [http://cultura2.gencat.cat/revistacultura/_pdf/28198805\%20Oriol\%20 Izquierdo.pdf].

Lluch, G. (2003) Análisis de narrativas infantiles y juveniles, Cuenca, Ediciones de la Universidad de Castilla-La Mancha.

Lluch, G. (2009) «Dades per a l'anàlisi de narratives per al lector infantil i juvenil», Caplletra, 46 (primavera), pp. 121-158. http://www.gemmalluch. com/portfolio-item/dades-per-a-lanalisi-de-narratives-per-al-lector-infantili-juvenil

Lluch, G. (2010) «Las nuevas lecturas deslocalizadas de la escuela», dins Lluch, G. (edt.) Las lecturas de los jóvenes. Un nuevo lector para un nuevo siglo, Barcelona, Editorial Anthropos, pp. 105-128.

Lluch, G. (2013) La lectura per a infants $i$ joves en català. Història, investigació i polítiques, Barcelona, Abadia de Montserrat.

Malé, J. (2007) «"Una llengua en plena ebullició". Els traductors davant el català literari a les primeres dècades del segle XX», Quaderns. Revista de traducció 14, pp. 79-94.

Martorell, A. (1987) «El llibre infantil», Faristol núm. 5 (desembre), pp. 6-21.

Nash, W. (1990) Language in popular fiction, London, Routledge.

Olrik, A. (1992) Principles for oral narrative research, Bloomington, Indiana University Press.

O'Sullivan, E. (2001) «Alice in different Wondernands: Varying approches in the German translations of an English children's classic», in Margaret Meek (edt.) Children's Literature and National Identity, UK, Trentham Books, pp. 11-22.

Pérez Latorre, Ó. (2007) «El bucle del arrepentimiento: Sobre la construcción del universo de ficción en Perdidos», en Carcajosa, C. (2007) La caja lista: televisión norteamericana de culto, Madrid, Laertes, pp. 117-130.

Rovira, T. (1976) Noucentisme i llibre infantil, Tesina de Llicenciatura. Facultat de Lletres, Bellaterra.

Rovira, T. (1988) «La literatura infantil i juvenil», dins Historia de la literatura catalana, volum 11, Barcelona, Ariel.

Rudd, D. (2000) Enid Blyton and the mystery of children's literatura, New York, Palgrave.

Sellent Arús, J. (1998) «La traducció literària en català al segle XX: alguns títols representatius», Quaderns. Revista de traducció 2, pp. 23-32.

Stephens, J. (1992) Language and ideology in children's fiction, London, Longman. 
Toutain, F. (1997) «Traducció i models estilístics» dins Traducció i literatura, Vic, Eumo, pp. 63-72.

Triadú, J. (1962) «Una edat sense llibres o una literatura sense futur», Serra d'Or núm. 8-9 (agost-setembre), pp. 34-35.

Valriu i Llinas, C. (1994) Història de la literatura infantil i juvenil catalana, Barcelona, Editorial Pirene.

Vila-Sanjuán, S. (2003) Pasando página. Autores y editores en la España democrática, Barcelona, Destino.

Vogler, C. (2002) El viaje del escritor. Las estructuras míticas para escritores, guionistas, dramaturgos y novelistas, Barcelona, Ediciones Robinbooks, 1998.

Zipes, J. (2001) Sticks and Stones. The troublesome Succes of Children's Literatura from Slovenly Peter to Harry Potter, Routledge, New York and London. 
